\title{
ВЛИЯНИЕ ОБЪЕКТА ПЕДАГОГИЧЕСКОЙ ДЕЯТЕЛЬНОСТИ НА ИЗМЕНЕНИЕ ПРОФЕССИОНАЛЬНО-ЛИЧНОСТНЫХ ХАРАКТЕРИСТИК УЧИТЕЛЯ: ДЕСТРУКТИВНЫЙ АСПЕКТ
}

\section{Желдоченко Людмила Дмитриевна Рогов Евгений Иванович}

В работе исследуются особенности изменения профессионально-личностных характеристик педагогов общеобразовательных школ и сочиальных приютов. В соответствии с авторской концепцией профессионализации, изменение профессионально-личностных характеристик рассматривается в пространстве, образованном тремя векторами, обозначенными как психологические особенности субъекта, особенности самой профессиональной деятельности, особенности объекта деятельности и взаимодействия с ним. Для фиксации различных поведенческих проявлений субъектов, оказывающих негативное влияние на развитие личности в профессиональной деятельности педагогов школы и педагогов социального приюта, использовались следующие стандартные методики: тест-опросник самоотношения В. В Столина, тест «Смысложизненные ориентации» Д. А. Леонтьева, тест «Удовлетворенность работой» В. А. Розановой, методика диагностики уровня эмоционального выгорания В. В. Бойко, опросник SACS - «Стратегии преодоления стрессовых ситуаций» С. Хобфолл, методика общей коммуникативной толерантности В. В. Бойко, тест на определение уровня агрессивности Басса-Дарки.

Полученные результаты свидетельствуют о наличии различий в деструктивных изменениях профессионально-личностных характеристик педагогов социального приюта в сравнении с педагогами общеобразовательной школы, что обусловлено спецификой профессиональной деятельности педагогов приюта, взаимодействием с психологически сложным объектом труда. Деструктивные изменения протекают по всем трем направлениям профессионализации. Психологические особенности личностно-смыслового компонента деструктивных изменений профессионального развития педагогов социального приюта характеризуются более низкими, по сравнению с педагогами общеобразовательной школы, показателями самоотношения и осмысленности жизни. Психологические особенности индивидуально-деятельностного компонента деструктивных изменений профессионального 
развития педагогов приюта проявляются в демонстрации крайней неудовлетворенности своей работой, ее условиями, организацией, возможностью карьерного роста, а также финансовой составляющей, по сравнению с педагогами общеобразовательных школ.

У педагогов социальных приютов более выражен синдром эмоционального выгорания: как показали результаты проведенного исследования, они чаще прибегают к асоциальным действиям в стрессовой ситуации. Коммуникативный компонент деструктивных изменений профессионального развития педагогов социальных приютов обнаруживается в более высокой интолерантности, более выраженных агрессивных реакциях, проявляющихся преимущественно через вербальную агрессию.

Ключевые слова: профессионализация, профессиональная деятельность, профессиональный стресс, профессиональная деформачия, эмочиональное выгорание, педагогическая агрессия, педагогическая деятельность, деформация личности, деформация деятельности, деформация взаимодействия.

\section{Введение}

Исследования процесса профессионального становления личности в разных профессиях достаточно широко представлены в научной литературе. Однако особое внимание, уделяемое исследователями проблеме профессионализации педагогов, не раскрывает специфику влияния на личность их воспитательной, предметной, возрастной направленности. Практически отсутствуют работы, изучающие профессиональные изменения педагогов социальных приютов, актуальность изучения которых обоснована важностью профессиональной деятельности педагогических кадров в ходе реабилитации и адаптации детей и подростков в обществе, значимостью личности педагога в процессе коррекции личностного развития воспитанников.

Проблема усугубляется нестабильным противоречивым состоянием современной системы социального обслуживания населения. С одной стороны, предъявляются высокие требования к качеству оказываемых услуг педагогами социальных приютов, с другой - достаточно низкий социальный статус профессии, текучесть и острая нехватка квалифицированных педагогических кадров, рост числа подопечных, склонных к девиациям, асоциальному поведению, имеющих отклонения в психосоматическом здоровье. Особенностью профессиональной деятельности педагога социального приюта является интенсивное эмоциональное взаимодействие со всеми участниками педагогического процесса. Регулярные стрессогенные ситуации, в которых пребывает педагог, погружение в сущность жизненных трудностей подопечных, высокая ответственность - все это пагубно сказывается на профессиональном развитии. 
В результате длительное пребывание в профессии, воздействие специфики профессиональной деятельности и влияние ее объекта искажают траекторию профессионального развития и детерминируют возникновение и развитие деструктивных изменений профессионально-личностных характеристик у педагога социального приюта. В связи с этим, сложилась насущная необходимость изучить психологические особенности деструктивных изменений профессионально-личностных характеристик педагога социального приюта, провести анализ факторов, детерминирующих возникновение и развитие деструктивных изменений в процессе профессионализации и способствующих формированию профессиональной деформации педагога социального приюта.

\section{0бзор литературы}

В современной науке учеными широко представлены теории педагогических систем, концепции профессионального становления личности (Н. В. Кузьмина, 1993; А. К. Маркова, 1994; Е. И. Рогов, 2014; В. А. Якунин, 1988, и др.) $[8,10,11,14]$. Основательно изучены деструктивные изменения профессионально-личностных характеристик, профессиональные деформации у педагогов общеобразовательных школ. Проблема нарушения профессионализации педагога изначально не была предметом научных исследований, а подразумевалась в рамках концепций профессионального развития (Ch. Buhler, 1971; J. L. Holland, 1973; D. Super, 1980, и др.), и только позднее изучалась исследователями как часть профессионального развития личности учителя $[17,20,22]$.

В дальнейшем это послужило предпосылкой для проведения комплексных исследований личностно-профессиональной деформации педагогов общеобразовательных школ (С. А. Дружилов, 2013; Э. Ф. Зеер, Э. Э. Сыманюк, 2005; А. К. Маркова, 1994; Е. И. Рогов, 2014, и др.) [3, 6, 10, 11].

Учеными установлено что, будучи значимой для человека, профессиональная деятельность оказывает заметное влияние на его ценностные ориентиры, смысложизненные установки, мотивы деятельности (И. В. Абакумова, 2002, 2003) $[1,15]$. Изучая отрицательное воздействие профессиональной деятельности на развитие личности учителя, Э. Ф. Зеер и Э. Э. Сыманюк применяют такое понятие, как «профессиональные деструкции» педагога. Исследователи тем самым расширяют представления о профессиональной деформации, присоединяя к данному понятию профессиональную отчужденность и некомпетентность, профессионально обусловленные акцентуации и выученную беспомощность. Среди наиболее распространенных профессиональных деформаций у школьных учителей ученые называют: педагогический догматизм, авторитарность, доминантность и др. (Э. Ф. Зеер и Э. Э. Сыманюк, 2005) [6]. 
По мнению авторов, именно эмоциональная напряженность школьного труда является одним из факторов развития деструктивных изменений профессионально-личностных характеристик педагога. Длительное напряжение может способствовать снижению психологической устойчивости человека, ослаблению его активности и в результате приводить к развитию деструктивных изменений профессионально-личностных характеристик, профессиональным деформациям (Р. М. Грановская, 1994; Э. Ф. Зеер, Э. Э. Сыманюк, 2005) [2, 6].

Большое количество исследований искажения профессионализации школьных учителей посвящено развитию негативных эмоциональных состояний и, в частности, агрессии в деятельности (M.-L. Chang, 2009) [18]. Doherty Erin Neave показано, что агрессивный педагог не только разрушительно воздействует на психику учащихся, но и являет собой пример для подражания и закрепления ответных агрессивных реакций, обогащая их поведенческий репертуар (E. N. Doherty, 2009) [19].

Боннер Дебора Л. установлено, что желание педагога добиться доминирующей позиции по всем позициям, угнетение, отсутствие веры в способности учащихся отрицательно сказываются не только на его поведении в классе, но и на Я-концепции его учеников и даже на их успеваемости (D. L. Bonner, 2010) [16].

Т. Е. Майорова установила взаимосвязь конфликтного поведения учителя в школе с уровнем его деформации. Учителя с высоким уровнем профессиональной деформации имеют низкий уровень конфликтной компетенции, что проявляется в авторитарном и манипулятивном взаимодействии в педагогическом процессе, в соперничестве и унижении ученика в ситуации конфликта, в демонстрации подозрительности, обидчивости, недоверия и недовольства другими (Т. Е. Майорова, 2010) [9].

Рассмотрение результатов научных исследований позволяет заключить, что педагоги общеобразовательных школ по роду своей деятельности вовлечены в длительное напряженное общение с обучающимися, их родителями, коллегами, а их профессиональный труд отличает высокая эмоциональная напряженность. В связи с этим, педагогической деятельности присущи деструктивные изменения профессионально-личностных характеристик, которые приводят к нарушению процесса профессионализации, снижают эффективность профессионального труда. Несмотря на различные подходы в исследовании искажения профессионального развития, большинство ученых едины во мнении, что педагогам присущи такие деструктивные изменения, как: авторитарность, демонстративность, дидактичность, педагогическая агрессия, формализм, консерватизм и др. (Л. Д. Желдоченко, 2015; Л. Д. Желдоченко, Е. И. Рогов, 2016; А. В. Козлова, 2006; Е. І. Rogov, Е. E. Rogova, 2015) $[4,5,7,21]$. 
В то же время проблема профессиональных изменений, происходящих с педагогами, работающими с детьми в других типах воспитательных учреждений, в частности в социальных приютах, проработана недостаточно. Психологические аспекты исследований, в основном, посвящены изучению профессиональных качеств, умений, профессиональной компетентности социальных работников (С. А. Дружилов, 2013) [13].

Главная отличительная особенность деятельности педагогов различных воспитательных учреждений определяется особенностями детей, иначе говоря - социально-психологическими особенностями объекта труда, с которыми осуществляется педагогическое взаимодействие. Характеризуя контингент социального приюта, Н. Б. Троицкая отмечает, что каждый ребенок, попавший в приют, психологически травмирован. Для большей части детей характерны задержка психического развития, педагогическая или социальная запущенность, различного рода девиации. Они не имеют необходимого социального опыта для полноценной жизни в обществе, вместе с тем их индивидуальный опыт отягощен различными негативными привычками (Н. Б. Троицкая, 2009) [12].

В отличие от учащихся общеобразовательных школ, дети и подростки, поступающие в приют, имеют различные отклонения в развитии, в познавательной сфере проявляющиеся в педагогической запущенности, задержке речевого и психоречевого развития, недоразвитии интеллекта. Нередко у них нарушена полоролевая социализация. Как правило, воспитанниками приюта становятся дети из асоциальных, неблагополучных семей, где они приобретают негативный социальный опыт: употребление психоактивных веществ, попрошайничество, бродяжничество, воровство, проституция и т. п. Такое ближайшее социальное окружение пагубно влияет на формирование личности ребенка, искажает его представления о здоровом образе жизни и социально приемлемых способах жизнедеятельности в целом (Л. Д. Желдоченко, 2015) [4].

Педагог социального приюта несет повышенную ответственность за жизнь и здоровье воспитанников, и это обстоятельство выступает для него тяжелым психологическим грузом. Ведь помимо того, что психотравмированному ребенку нужно оказать поддержку, в том числе и психологическую, завоевать его доверие, расположить к себе с целью проведения реабилитационных мероприятий, педагог должен постоянно держать под контролем жизненную ситуацию этого воспитанника. Одновременно педагог обязан выполнять свои профессиональные обязанности и по отношению к другим воспитанникам, у которых, возможно, не менее сложные проблемы. Во время пребывания воспитанников в приюте задача всех специалистов, работающих с ними, и педагогов в первую очередь, заключается в реабилитации, 
адаптации подопечных в социуме, перевоспитании детей и подростков путем вовлечения их в здоровую систему социального взаимодействия. Важная задача педагогов состоит в том, чтобы показать подопечным, что есть другая система ценностей, другая система взаимоотношений - без насилия, без агрессии (Л. Д. Желдоченко, Е. И. Рогов, 2016) [5].

Профессиональная деятельность педагога приюта связана с высоким уровнем эмоционально-стрессовых нагрузок и повышенной моральной ответственностью. Это создает чрезмерное психологическое напряжение, способное привести к появлению у педагогических работников признаков эмоционального выгорания, развитие которых способствует повышению раздражительности, снижению фрустрационной толерантности, возникновению неудовлетворенности профессией, утрате перспектив профессионального роста. Эмоциональное истощение способствует потере мотивации и работоспособности, что может привести к регрессу профессиональной деятельности. Кроме того, специфика профессиональной деятельности педагога состоит в том, что она основывается на активном общении, включающем интенсивное эмоциональное взаимодействие. Учитывая вышесказанное, без сомнения можно утверждать, что педагоги социального приюта относятся к «группе риска» по вероятности возникновения и развития деструктивных изменений профессионально-личностных характеристик, профессиональной деформации.

Резюмируя вышеизложенное, можно заключить, что специфику профессиональной деятельности педагога социального приюта обуславливают такие факторы, как эмоциогенная напряженность профессионального труда и интенсивное эмоциональное взаимодействие, психологически трудный объект труда, повышенная ответственность за исполняемые обязанности. С увеличением стажа работы это, вероятно, приводит к развитию деструктивных изменений профессионально-личностных характеристик, профессиональной специфической деформации педагога социального приюта.

\section{Методы и методики исследования}

Согласно концепции Е. И. Рогова, личностно-профессиональное развитие педагога протекает в сложном объемном трехмерном профессиональном пространстве, образованном тремя векторами, обозначенными как психологические особенности субъекта, особенности самой профессиональной деятельности, а также третьим вектором, определяемым как специфические особенности объекта деятельности и взаимодействия с ним. Пересекаясь в пространстве, векторы, обозначенные как «личность специалиста» и «профессиональная деятельность», образовывают плоскость, куда входит все многообразие вариантов индивидуальных стилей деятельности 
профессионалов, оказывающих влияние на профессионально-личностные характеристики педагогов (Е. И. Рогов, 2014) [11].

Соответственно, можно утверждать, что развитие отклонений у профессионала также будет происходить в рамках данного пространства профессионализации и протекать по трем направлениям: нарушение деятельности, разрушение личности, дефекты профессионального взаимодействия. Так, деструктивные изменения личностных характеристик отражает личностно-смысловой компонент, деструктивные изменения профессиональных характеристик - индивидуально-деятельностный компонент, а деструктивные изменения профессионального взаимодействия - коммуникативный компонент.

Для изучения разнообразных личностных поведенческих проявлений, оказывающих негативное влияние на развитие личности в профессиональной деятельности педагогов школы и педагогов социального приюта, использовались следующие методики: тест-опросник самоотношения В. В. Столина, тест «Смысложизненные ориентации» Д. А. Леонтьева для изучения личностносмыслового компонента, тест «Удовлетворенность работой» В. А. Розановой, методика диагностики уровня эмоционального выгорания В. В. Бойко, опросник SACS - «Стратегии преодоления стрессовых ситуаций» (С. Хобфолл) для изучения индивидуально-деятельностного компонента, методика общей коммуникативной толерантности В. В. Бойко, тест на определение уровня агрессивности Басса-Дарки для изучения коммуникативного компонента. При осуществлении математической обработки использовалась компьютерная программа статистического анализа и обработки SPSS v. 21.

Экспериментальная база исследования. В исследовании приняли участие 210 респондентов, из них - 60 педагогов общеобразовательных школ г. Батайска Ростовской области и 150 педагогов социальных приютов Ростовской области. Выборка респондентов социального приюта включает 138 женщин и 12 мужчин, 73 \% из них имеют высшее педагогическое образование и $27 \%$ - среднее профессиональное педагогическое. По стажу работы выборка разделена на 3 группы по 33 \% каждая - до 5 лет работы в социальном приюте, от 5 до 10 лет и более 10 лет работы. Из 60 педагогов общеобразовательных школ - 57 женщин и 3 мужчин. Высшее педагогическое образование имеют 85 \% респондентов, среднее профессиональное педагогическое - 25 \% обследуемых. Выборка испытуемых разделена по стажу работы на три равные группы по 33,3 \%. Это педагоги со стажем до 5 лет работы, от 5 до 10 и более 10 лет работы в общеобразовательной школе. Исследовательской базой выступило Государственное бюджетное учреждение социального обслуживания населения Ростовской области «Центр социальной помощи семье и детям» г. Ростова-на-Дону. 


\section{Результаты и дискуссия}

Изучение личностно-смыслового компонента деструктивных изменений профессионально-личностных характеристик педагогов показало разную степень выраженности структурных компонентов самоотношения у педагогов социального приюта и общеобразовательной школы. Установлены достоверно значимые различия по трем компонентам самоотношения на уровне конкретных действий в отношении к своему Я: «самоуверенность», «самоинтерес», «самопонимание» и по шкале «самоинтерес». В ходе исследования доказано, что педагогов социальных приютов отличают более низкие показатели самоотношения.

В ходе анализа результатов исследования смысложизненных ориентаций педагогов социальных приютов и общеобразовательных школ выявлен интересный факт: в обеих группах испытуемых отмечается достаточно высокий общий уровень осмысленности жизни. Это позволяет утверждать типичность для педагогов наличия целей в будущем, которые придают их жизни разную степень осмысленности и временную перспективу.

В показателях «результативность жизни» выявлены достоверные различия, согласно которым педагоги социального приюта в большей степени ориентированы на прошлое. Прожитая часть жизни оценивается ими как наиболее продуктивная и результативная. Анализируя показатели осмысленности жизни, важно отметить, что у педагогов приюта они ниже, чем у педагогов общеобразовательной школы.

Изучение индивидуально-деятельностного компонента деструктивных изменений профессионально-личностных характеристик педагогов позволило выявить достоверно значимые различия по таким симптомам, как: «переживание психотравмирующих обстоятельств», «неудовлетворенность собой», «неадекватное избирательное эмоциональное реагирование», «эмоциональный дефицит», «эмоциональная отстраненность» и «психосоматические и психовегетативные нарушения». Важно отметить, что вышеперечисленные симптомы в большей степени переживаются педагогами социальных приютов, что обусловлено спецификой их профессионального труда.

Согласно полученным данным, для педагогов социального приюта характерен более высокий уровень сформированности как отдельных симптомов, так и фаз синдрома эмоционального выгорания. У них выработан более выраженный механизм психологической защиты, чем у педагогов школ. Их отличает практически сформированный стереотип профессионального поведения, позволяющий дозировать и экономно расходовать эмоционально-энергетические ресурсы. Это приводит к формированию дисфункциональных следствий синдрома у педагогов приюта и негативно отражается на выполнении профессиональной деятельности. 
Анализ результатов исследования степени удовлетворенности своей работой педагогов социальных приютов и общеобразовательных школ показал, что достоверно значимые различия выявлены в частоте встречаемости таких оценок, как «не вполне удовлетворен» и «крайне не удовлетворен» работой. Доказано, что педагоги социальных приютов чаще выражают неудовлетворенность и крайнюю неудовлетворенность своей работой, ее условиями, организацией, возможностью карьерного роста, а также финансовой составляющей, в сравнении с педагогами общеобразовательных школ.

Проведенный анализ результатов стратегий преодоления стрессовых ситуаций позволил установить достоверно значимые различия в копингстратегиях педагогов социальных приютов и общеобразовательных школ по следующим стратегиям: «импульсивные действия», «избегание» и «асоциальные действия». Это говорит о том, что педагогов социальных приютов отличает избегание решительных действий, уход от конфликтных ситуаций, стремление откладывать разрешение проблемных ситуаций. Важно отметить, что несмотря на преобладание в обеих исследовательских группах просоциальных моделей поведения, для педагогов социальных приютов характерна более выраженная склонность действовать по первому побуждению без предварительного анализа проблемной ситуации, они в большей степени склонны выходить за социально допустимые рамки и ограничения в стрессовых ситуациях.

Установленные различия по отдельным стратегиям поведения педагогов в стрессовых ситуациях позволили достоверно точно установить тот факт, что степень конструктивности преодолевающего поведения педагогов социального приюта, в целом, ниже, чем у педагогов общеобразовательных школ.

Исследование психологических особенностей коммуникативного компонента деструктивных изменений профессионально-личностных характеристик выявило достоверно значимые различия в уровне «вербальной агрессии» и «подозрительности» педагогов. Отмечено преобладание вербальной агрессии у педагогов социальных приютов и подозрительности у педагогов общеобразовательных школ. Расчет индексов враждебности и агрессивности в группах педагогов, осуществленный на основании установленных показателей, достоверно доказывает, что для педагогов общеобразовательных школ характерна негативная позиция по отношению к участникам педагогического процесса, а педагогов социальных приютов отличает склонность к агрессивным реакциям, преимущественно вербальным, по отношению к обучающимся и коллегам.

Изучение коммуникативной толерантности испытуемых обеих групп позволяет утверждать, что педагогам социального приюта свойственна достаточно низкая терпимость к участникам педагогического процесса 
в различных ситуациях. В ходе исследования установлены достоверные различия по следующим направлениям взаимодействия: «тенденция оценивать людей, используя себя в качестве эталона», «категоричность в оценках других», «способность скрывать неприятные впечатления от общения с некоммуникабельными людьми», «терпимость к дискомфортным состояниям окружающих» и «адаптационные способности». Таким образом, полученные результаты свидетельствуют о более низкой коммуникативной толерантности педагогов социальных приютов, как по отдельным компонентам, так и в целом, в сравнении с педагогами общеобразовательных школ.

Далее нами было проведено исследование особенностей деструктивных изменений профессионально-личностных характеристик у педагогов социального приюта с разным стажем работы по каждому структурному компоненту. Достоверно точно установлено, что стаж значимо коррелирует со всеми интегративными показателями личностно-смыслового, индивидуально-деятельностного и коммуникативного компонентов профессиональноличностных характеристик педагогов социальных приютов. Таким образом, можно заключить, что с увеличением стажа работы педагогом в социальном приюте значительно снижаются показатели самоотношения и осмысленности жизни, сужается репертуар просоциальных копинг-стратегий поведения в стрессовых ситуациях. Наряду с этим, повышается интолерантность, отмечается рост агрессивности и враждебности, усиливается степень выраженности синдрома эмоционального выгорания.

\section{Заключение}

В результате проведенного эмпирического исследования удалось достоверно точно установить тот факт, что увеличение педагогического стажа неизбежно приводит к нарушению процесса профессионализации. Детерминирующими факторами искажения профессионального становления педагога социального приюта выступают повышенная психоэмоциональная напряженность педагогической деятельности и психологически сложный объект труда.

Доказано, что деструктивные изменения профессионально-личностных характеристик педагога социального приюта развиваются по трем направлениям: нарушение деятельности, нарушение личности, нарушение профессионального взаимодействия.

Признаки деструктивных изменений деятельности отражает индивидуально-деятельностный компонент. В профессиональной деятельности это проявляется через деперсонализацию, нарушение функций самоконтроля, редукцию профессиональных обязанностей и эмоциональную отстраненность. Деструктивные изменения личности отражает личностно-смысловой 
компонент, что проявляется в искажении ценностных ориентаций, нарушении целеполагания и прогнозирования, снижении или утрате позитивного самоотношения, нарушении целостности личности, ее адаптивности. Деструктивные изменения профессионального взаимодействия с объектом труда отражает коммуникативный компонент, что проявляется в профессиональной деятельности как значительное снижение толерантности к окружающим и утрата навыков конструктивного взаимодействия.

Психологические особенности деструктивных изменений профессионально-личностных характеристик педагогов социального приюта, в сравнении с педагогами общеобразовательной школы, отражены в каждом структурном компоненте профессиональной деформации:

- на уровне личностно-смыслового компонента - более низкие показатели самоотношения и осмысленности жизни по сравнению с педагогами общеобразовательной школы;

- на уровне индивидуально-деятельностного компонента - большая неудовлетворенность и крайняя неудовлетворенность своей работой во всех ее аспектах, более выраженный синдром эмоционального выгорания в сравнении с педагогами общеобразовательных школ;

- на уровне коммуникативного компонента - высокая интолерантность и выраженность агрессивных реакций, преимущественно вербальных, в сравнении с педагогами общеобразовательной школы.

Проведенное исследование позволило более подробно изучить деструктивные изменения профессионально-личностных характеристик в педагогической профессии, исследовать психологические особенности деструктивных изменений профессионально-личностных характеристик педагогов социального приюта в сравнении с педагогами общеобразовательной школы. Полученные результаты позволили углубить и расширить научные представления о процессе профессионального развития педагога социального приюта.

Практическая значимость представленных материалов заключается в возможности их использования в работе практикующих психологов, педагогов-психологов при разработке программ психологического сопровождения профессионального развития педагогов социального приюта с целью предупреждения деструктивных процессов на разных этапах профессионализации, с целью повышения эффективности деятельности.

\section{Литература}

1. Абакумова И. В. Толерантность и личностный смысл как сопряженные характеристики образовательного процесса // Материалы регионального научно-практического семинара. - Ростов н/Д, 2002. - С. 98-103. 
2. Грановская Р. М. Творчество и преодоление стереотипов. - СПб., 1994. 179 c.

3. Дружилов С. А. Концептуальная модель профессиональной деятельности как психологическая детерминанта профессионализма // Психологические исследования. - 2013. - Т. 6. - № 29. - С. 4.

4. Желдоченко Л. Д. Психологические особенности профессиональной деформации педагога социального приюта: дисс. ... канд. психол. наук. - Ростов н/Д, 2015. - 169 с.

5. Желдоченко Л.Д., Рогов Е. И. Профессиональные деформации в педагогической деятельности (на примере педагогов социального приюта). - М.: Изд-во ЮФу, 2016. - 248 с.

6. Зеер Э. Ф., Сыманюк Э. Э. Психология профессиональных деструкций. М.: Академический проект, 2005. - 240 с.

7. Козлова А. В. Психологические особенности профессиональных деформаций преподавателя высшей школы: дисс. ... канд. психол. наук. - М., 2006. - 120 c.

8. Кузьмина Н. В., Реан А. А. Профессионализм педагогической деятельности. - СПб., 1993. - 263 с.

9. Майорова Т. Е. Формирование конфликтной компетентности педагогов, имеющих профессиональную деформацию: дисс. ... канд. психол. наук. - СПб., 2010. - 223 с.

10. Маркова А. К. Психология труда учителя. - М., 1994. - 308 с.

11. Рогов Е. И. Психология становления профессионализма. - Ростов н/Д: Фонд поддержки образования, 2014. - 360 с.

12. Троицкая Н. Б. Педагогическая поддержка подростков в условиях приюта: дисс. ... канд. пед. наук. - М., 2009. - 174 с.

13. Фирсов М. В. Психология социальной работы: содержание и методы психосоциальной практики. - М.: Юрайт, 2013. - 419 с.

14. Якунин В. А. Обучение как процесс управления: психологические аспекты. - Л.: Изд-во ЛГУ, 1988. - 160 с.

15. Abakumova I. V., Yermakov P. N. On development of a tolerant personality in multicultural education // Questions of Psychology. - 2003. - Issue 3. pp. 78-82.

16. Bonner D. L. Do individual differences matter? Individual differences and teachers' perceptions of physical and social aggression. - Richardson: The University of Texas at Dallas Publ., 2010. - 129 p.

17. Buhler Ch. Basic Theoretical conceptions of Humanistic Psychology // American Psychol. - 1971. - V. 26. - № 4. - pp. 378-386.

18. Chang M.-L. Teacher emotion management in the classroom: Appraisal, regulation, and coping. - Columbus: The Ohio State University, 2009. - 140 p. 
19. Doherty E. N. Self-efficacy and relational aggression: An examination of general and special education teachers: Dissertation. - San Diego: Alliant International University Publ., 2009. - 161 p.

20. Holland J. L. Haking vocational choice // A theory of careers. - N. Y., 1973.

21. Rogov E. I., Rogova E. E. Professional Ideas as Factor of Attitude towards Performed Activity // Asian Social Science. - 2015. - V. 11. - no. 8. pp. 233-242.

22. Super D. A. Life-span, life-space approach to career development // Journal of Vocational Behavior. - 1980. - V. 16. - pp. 282-298. 